\title{
O PÉ BIOGRÁFICO E A CONSTITUIÇÃO DA AUTORIA EM ARTIGOS DE JORNAL
}

\author{
Francisco Alves Filho*
}

\begin{abstract}
Resumo: O objetivo deste estudo é observar a constituição da autoria em artigos de jornal quando sua constituição é produzida pelos próprios articulistas, especialmente através dos modos de elaboração do pé biográfico. O corpus é constituído por artigos publicados nos jornais O Dia, Meio Norte e Diário do Povo, os quais circulam nos estados do Piauí e Maranhão. Duas regularidades emergiram do material pesquisado: o fato de um mesmo autor construir diferentes pés biográficos para diferentes textos por ele assinados e a ocorrência de pés biográficos contendo dados que emergem dos e reportam aos próprios textos. Vista no conjunto dos artigos investigados, a constituição da autoria aponta para traços da cultura do lugar social onde os jornais circulam, sendo um deles o saliente acento valorativo conferido à formação acadêmica dos articulistas.
\end{abstract}

Palavras-chave: artigo jornalístico; autoria; pé biográfico; gênero discursivo; jornal.

\section{INTRODUÇÃO}

A relevância de se estudar a autoria ${ }^{1}$ (e os autores), como apontou Foucault (1969, p. 32), reside no fato de se poder encontrar explicações para "as condições de funcionamento de práticas discursivas

\footnotetext{
* Professor da Universidade Federal do Piauí. Doutor em lingüística, chicofilhoo@gmail.com

1 Do ponto de vista teórico afigura-se como bastante complexo distinguir com objetividade as noções de autoria e autor porque muitas vezes, na prática, ambas se confundem e determinam uma à outra constantemente. Ainda que intuitivamente, trabalharemos aqui com uma distinção mínima, fundada essencialmente no grau de abrangência de ambas: tomaremos a autoria prioritariamente como o fenômeno mais geral de responsabilização enunciativa e jurídica dos textos, estando fortemente vinculada aos gêneros do discurso. Já a noção de autor será vista de modo mais particular, estando fortemente vinculada aos enunciados concretos.
} 
específicas", sendo que isso se torna possível pelo fato de que as diversas práticas enunciativas têm, na figura do autor, tanto um ponto de partida como um ponto de chegada. Ou seja, do ponto de vista de quem produz um enunciado ${ }^{2}$, sua postura de autor funciona como um ponto de partida - produzir enunciados, até certo ponto, consiste em desempenhar um determinado papel de autoria, o qual se acha prefigurado nas práticas sociais de linguagem, sendo materializado pelos gêneros do discurso. E, da perspectiva dos interlocutores, a figura do autor é um ponto de chegada, pois ela funciona como um "cartão postal" - é através dos autores e em seu nome que os enunciados chegam até os interlocutores, o que é extremamente relevante para o processo de compreensão responsiva e de apreciação valorativa.

A não ser que os textos funcionem discursivamente fundados no anonimato, os interlocutors, no geral, se preocupam em saber quem são os autores do texto e fazem uso estratégico do que sabem sobre eles, tanto para atribuir sentido aos enunciados como para, em relação a eles, produzir réplicas. Entretanto, mesmo nos casos de anonimato, podemos sustentar que, justamente por funcionarem sistematicamente sem menção a autores empíricos, temos um tipo específico de autoria, o qual também pode ser estrategicamente usado pelos interlocutores. Por exemplo, se um texto circula anonimamente os interlocutores podem duvidar de sua veracidade e não levá-lo a sério - sobretudo se tiver um tom acusatório ou difamatório; por outro lado, esses textos podem possibilitar ainda que verdades questionáveis sejam veiculadas sem questionamento - caso dos provérbios e lendas. Como se vê, estamos propondo aqui uma ampliação da noção de autoria de modo a tentar dar conta da complexidade que lhe é constitutiva, dado que a autoria é uma categoria construída por vários atores sociais: locutores, interlocutores, crítica. Embora muitas vezes fiquem marcas da autoria nos próprios enunciados, como é o caso do pé biográfico aqui estudado, nem sempre isso ocorre. Entretanto, se os locutores assumem algum tipo de responsabilidade pelos enunciados ou uma razão para a omissão dessa responsabilidade, seguramente estão lidando estrategicamente com a

2 Optamos pelo termo enunciado, ao invés de texto, mas dando a ele o sentido que lhe oferece Bakhtin (1992), ou seja, um enunciado concreto proferido numa situação concreta de comunicação concreta e dirigido a um horizonte social. Com isso, esperamos evitar um sentido abstrato e estrutural para os enunciados.

ALVES FILHO - O pé biográfico e a constituição... 
noção de autoria. Não é objetivo deste trabalho discutir este ponto, mas o funcionamento da autoria em textos que circulam anonimamente também pode oferecer explicações relevantes para esta categoria.

Em todo caso, parece-nos que a noção de autoria reveste-se de uma importância nada desprezível para os estudos enunciativos que se apóiam teoricamente na noção de gêneros do discurso: ao se considerar que a comunicação humana se efetiva através de tipos históricos de enunciados, faz-se necessário considerar também que estes enunciados circulam sempre exibindo (ou presumindo) uma dada concepção de autoria. Mas é claro que a autoria não deve ser confundida com o locutor ou com quem assina o texto. Tomamos a autoria aqui como uma categoria enunciativa, existente apenas nos enunciados e nos gêneros de discurso, a qual depende de um jogo representacional. Ninguém é a priori um autor: cada um pode, dependendo de pré-requisitos sóciohistóricos, desempenhar uma certa função de autor. Em face disso é que seria extremamente redutor supor que o autor pudesse corresponder apenas ao indivíduo empírico produtor de enunciados.

Assim, o objetivo deste artigo é buscar identificar algumas regularidades quanto à forma como os articulistas constroem o pé biográfico (a síntese biográfica apresentada ao final do artigo) para seus próprios textos, buscando explicar, do ponto de vista sociocultural, as razões para estas escolhas. Os dados - 90 artigos dos principais jornais da cidade de Teresina - pertencem a uma mesma seção dos jornais e foram publicados numa mesma época. Os artigos foram coletados aleatoriamente para que fosse possível observar tendências e regularidades. A análise foi feita exclusivamente sobre o pé biográfico, observando as esferas de atividades às quais os articulistas se vinculam e como estas informações são organizadas.

$\mathrm{O}$ artigo é composto de duas seções. Na primeira faz-se a discussão das relações teóricas entre autoria e gêneros do discurso, enfatizando os modos como tanto interlocutores como autores colaboram para sua construção. Na segunda seção - de cunho analítico investiga-se o papel do pé biográfico para a constituição da autoria em artigos de jornal. A metodologia da análise é apresentada ao longo do texto. 


\section{REFERENCIAL TEÓRICO}

\subsection{A pré-configuração da autoria estabilizada relativamente nos gêneros}

Seguindo muito de perto a visão teórica de Bakhtin (1979a, 1979b), defendemos e propusemos em pesquisas anteriores alguns outros desdobramentos teóricos (ALVES FILHO, 2005, 2006) para a tese de que os gêneros prefiguram, cada um a seu modo, uma determinada concepção de autoria. Mas, dada a sua incompletude, esta assunção será aqui revista de modo a incorporar o fato de que, embora prefigurada nos gêneros, a autoria é construída através de uma complexa interação que envolve o modo como o próprio autor aponta para si nos enunciados e o modo como os interlocutores os representam sociocognitivamente. Mas é claro que autores e interlocutores trabalham não num vácuo enunciativo-genérico, e sim tendo como horizonte de perspectiva os gêneros do discurso e as práticas sociais de linguagem que os gêneros, a um só tempo, possibilitam e por elas são possibilitados. Por esta razão, estamos aqui defendendo que a autoria precisa ser investigada em sua interface com os gêneros de discurso e com as categorias que estes pressupõem.

Como já tem sido amplamente discutido nas últimas décadas ${ }^{3}$, nas práticas sociais os gêneros de discurso servem para estabilizar (relativamente) as rotinas e as interações sociais, e, como decorrência disso, os próprios gêneros vão incorporando um conjunto de características funcionais e formais com algum grau de estabilidade (cf. BAZERMAN, 2005; BATHIA, 1997). Por esta razão é que, para realizar determinados atos retóricos, os sujeitos preferem alguns gêneros a outros, assim como, ao lerem ou ouvirem textos e perceberem alguns traços formais, fazem logo um cálculo enunciativo a respeito do gênero de discurso em jogo e, conseqüentemente, passam a inferir intuitos discursivos, temas e interesses ideológicos. É muito provável que grande

\footnotetext{
${ }^{3}$ Embora através de enfoques teóricos e metodológicos diferentes, as diversas teorias de gêneros do discurso se aproximam ao defenderem que a relação entre os gêneros e as práticas sociais não se dão de modo unilateral. Em Bakhtin, Bazermam e Bathia, por exemplo, essa abordagem dinâmica pode ser percebida.
} 
parte destas inferências sejam realizadas com base nas categorias genéricas que se estabilizam relativamente: leitor presumido, temas ideologicamente conformados, lugar enunciativo e tempo enunciativo, intuito discursivo e autoria. É nesta última categoria que focaremos este estudo, buscando lançar alguma luz sobre o modo como os autores colaboram para a construção de sua representação de autor no interior dos enunciados, mas tendo em mira um horizonte sócio-axiológico concreto configurado pelos gêneros do discurso.

Estamos tomando como hipótese de trabalho o fato de que os gêneros do discurso presumem uma determinada configuração de autoria, a qual tanto serve como um guia enunciativo para os produtores de texto-discurso (oral e escrito), como para os leitores e ouvintes. Com isso postulamos que os sujeitos, ao produzirem suas ações comunicativas, procuram, via de regra, comportar-se enquanto autores de um certo feitio enunciativo, seja realizando determinados atos sócioretóricos, seja justificando as ações que não serão realizadas. Por seu turno, os leitores-ouvintes, ao oferecerem suas contra-palavras aos enunciados, guiam-se estrategicamente pelo tipo de autoria associada aos enunciados, de modo a prever intuitos discursivos e tornar mais significativa a sua interação.

Portanto, podemos dizer que a autoria encontra-se já grandemente prefigurada pelos próprios gêneros, embora possa sofrer reenquadramentos enunciativos tanto por parte dos autores empíricos, como do conjunto de leitores/ouvintes. Por esta razão é que uma tarefa descritivo-explicativa grandemente relevante, no estudo dos gêneros, é tanto oferecer explicações para a autoria neles presumida como investigar como esta autoria se materializa empiricamente e funciona nas trocas comunicativas concretas.

\subsection{O papel dos interlocutores na construção da autoria}

Um comportamento recorrente dos interlocutores é elaborar uma representação do autor do enunciado (oral ou escrito) com o qual interagem em dado momento comunicativo. E se eles assim procedem é porque a representação do autor funciona como uma poderosa ferramenta enunciativa para a compreensão e elaboração de reaçõesrespostas aos enunciados - ou seja, no geral, importa, e muito, quem 
fala. Qualquer pessoa que alterar o nome do autor de um texto e o submeter a processos de leitura poderá constatar que, por se guiarem por representações diferentes de autores, os interlocutores reagirão diferentemente a estes textos ${ }^{4}$. Tal representação do autor construída pelo interlocutor pode fundar-se tanto nos indícios oferecidos pelos enunciados como em outros saberes acerca dos autores empíricos, da situação comunicativa e/ou do contexto sócio-histórico mais amplo. Desse modo - por fundar-se em conhecimentos de ordens diversas - é que tanto pode haver convergência como divergência entre a representação do autor feita pelo interlocutor, a pretensão de autoria do próprio autor empírico e a autoria prefigurada nos gêneros.

É de se esperar que este processo de representação da autoria pelos interlocutores seja marcado ideologicamente e produzido pelos seus sistemas de crenças e valores. Isso faz com que tal representação do autor em cada enunciado concreto seja afetada por representações anteriores, de modo que a própria réplica aos enunciados seja influenciada por este duplo processo. Foucault (1969) referiu-se muito bem a este fenômeno ao mostrar que o autor "bordeja os textos", funcionando como um "foco de coerência" para eles. É claro que este processo tem mais vitalidade, como esclarecido pelo próprio Foucault, quando ocorre em obras de grandes autores: como elas são incessantemente lidas por conjuntos enormes de leitores e de críticos especializados, cada novo leitor pode passar a lidar com a representação de autoria já realizada por outros leitores e ser por ela influenciado. Temse, neste caso, uma representação de autoria largamente estabilizada e consagrada numa dada esfera de comunicação humana.

Tem-se assim um processo de mútua influência: é quando a representação da autoria assume um papel decisivo (e perigoso, muitas vezes) nos processos de reação-resposta aos enunciados, pois pode sobredeterminar os enunciados e impedir uma interação fundada mais

${ }^{4}$ Relato brevemente aqui uma experiência que realizei uma vez. Ministrando um curso para professores na cidade de Teresina, apresentei a eles duas letras de músicas: uma originalmente do músico brasileiro Chico Buarque, mas não muito conhecida, como se fosse de autoria de Leandro e Leonardo, dois cantores de música sertaneja. A outra, originalmente de Leandro e Leonardo, foi apresentada aos professores como se fosse de autoria de Chico Buarque. Como era de se esperar, a letra de Leandro e Leonardo foi interpretada como se contivesse um tom político metaforicamente disfarçado e a outra música foi tomada como se apenas retratasse um caso amoroso.

ALVES FILHO - O pé biográfico e a constituição... 
diretamente naquilo que figura de modo saliente nos enunciados. Uma situação limite deste caso seria: ao aceitar que um autor $\mathrm{X}$ é genial, enxergar apressadamente genialidade em tudo que por ele foi escrito, sem dar-se ao trabalho de ler com acuidade os enunciados por ele produzidos - o que ocorre com freqüência nas esferas artística, midiática e escolar. Ou, na mão contrária, por lidar com uma representação negativa de um autor $y$, não enxergar valores positivos naquilo que ele escreve, mesmo quando isso textualmente possa ter ocorrido - o que se dá com freqüência nas esferas do ensino básico uma vez que o aluno não é visto como um autor, mas como um errante aprendiz.

\subsection{O trabalho do autor empírico para a construção da autoria}

Como não poderia deixar de ser (e seria mesmo absurdo se assim não o fosse), tanto os autores empíricos - aqueles que realizam a tarefa material-semiótica de construir enunciados - como os autores enunciativos - aqueles que assumem discursivamente os enunciados são co-responsáveis pela representação da autoria do texto. Tomemos como exemplo o caso em que o gerente de uma instituição solicita a um funcionário que produza um texto a ser distribuído aos consumidores. Via de regra, o funcionário-redator - como autor-empírico - buscará dar um tratamento ao tema de forma condizente com a posição que defende a empresa (o autor-enunciativo nesta situação), tentando, ao máximo, dizer com exatidão o que a empresa pretende enunciar. Mas é possível que o autor empírico diga "a mais" ou diga "a menos", de forma deliberada ou não, o que serve para exemplificar o fato de que a autoria dos textos passa por processos complexos e que somente pode ser bem compreendida se for concebida como de natureza sócio-ideológica ${ }^{5}$.

Extremamente relevante nesta discussão é apontar que a forma primeira de assumir a responsabilidade autoral se dá quando o sujeito opta ou é compelido a adotar determinado gênero de discurso e, conseqüentemente, investe-se da figura de autor que este mesmo gênero

\footnotetext{
${ }^{5}$ A respeito desta descontinuidade entre autor-empírico e autor-enunciativo, encontramos dois casos relevantes nos editoriais do Jornal Meio Norte, que circula em Teresina-PI. Estes dois textos discutem o papel dos jornalistas na época da repressão militar no Brasil, na década de 1970, mas, em vez de o fazê-lo, como é o mais esperado neste gênero, do ponto de vista institucional, o redator o fez do ponto de vista saudosista individual.
} 
presume. Ou quando, deliberadamente, propõe um reenquadramento da autoria típica do gênero, recusando-se a apenas ocupar uma posição de autor já prefigurada nos gêneros. Em trabalho anterior (ALVES FILHO, 2005), fizemos referência a este último processo ao mostrar como, em algumas colunas de opinião assinadas ${ }^{6}$ do Jornal Folha de S. Paulo, os colunistas não se comportam "prototipicamente" como colunistas, mas como fabulistas, missivistas, acadêmicos etc. Com isso, os autores provocam, simultaneamente, um reenquadramento no gênero e na autoria. Os leitores podem indagar-se a respeito de qual gênero têm diante de si pelo fato de que traços composicionais e estilísticos não previstos (ou não relativamente estabilizados) para as colunas de opinião passam a figurar neles. E podem também indagar-se a respeito da posição da autoria: trata-se de alguém falando em causa própria, em nome de uma empresa, como jornalista?

Um segundo modo de contribuir com a elaboração da autoria dáse através das formas como o articulista faz o texto apontar para ele próprio (sem excluir os casos em que o autor enunciativo não aponta de nenhum modo para o autor-empírico). Ou seja, é quando o texto, internamente, aponta para uma figura anterior, posterior ou exterior aos textos, ou seja, um ente do mundo extra-textual. Os recursos lingüísticos que tipicamente se prestam a esta função são os diversos tipos de pronomes de primeira pessoa do singular e do plural (eu, me, mim, meu, nós, nos, nosso). Também servem para materializar esta função os relatos de experiência pessoal e, no caso específico dos artigos de opinião, o pé biográfico, que é uma brevíssima biografia do articulista publicada abaixo ou acima do texto.

\subsection{A autoria nos gêneros opinativos na imprensa escrita}

Melo (1994) defende que o modo de constituição da autoria se mostra extremamente relevante para caracterizar e explicar o funcionamento dos gêneros opinativos da imprensa escrita - editorial, artigo, coluna e carta de leitor. Isso ocorre por que eles são muito

\footnotetext{
${ }^{6}$ Estamos denominando de colunas de opinião assinadas os textos de caráter opinativo publicados periodicamente nos jornais, em sessão fixa - mesma página e mesmo lugar na página -, assinados por um jornalista que trabalha para a empresa jornalística. Para mais detalhamento desta nomeação o leitor pode consultar Melo (1994) e Alves Filho (2005).
}

ALVES FILHO - O pé biográfico e a constituição... 
semelhantes do ponto de vista temático - falam sobre fatos recentes e relevantes para uma dada sociedade; estilístico - presença recorrente de adjetivação, operadores argumentativos, voz passiva; composicional presença do esquema apresentação resumida de um fato, desenvolvimento de argumentação para demonstrar uma tese e conclusão; e ideológico - dar a entender que vivemos numa sociedade marcadamente democrática, participativa e com liberdade de expressão de idéias. Dado este conjunto de semelhanças, o que explica suas diferenças e marca sua identidade genérica é o fato de admitirem e exibirem modos distintos de configuração da autoria.

Assim, enquanto o que serve para produzir a identidade genérica do editorial é o fato de ele possuir uma autoria institucional assumida internamente pela própria empresa e pelo veículo de comunicação em que é publicado, a coluna de opinião assinada apresenta uma autoria de tipo sócio-profissional: o colunista fala (ou pode falar) em primeira pessoa e em seu próprio nome, mas enquanto um jornalista, pertencente a um segmento classista-profissional. A autoria na coluna de opinião tem um caráter híbrido pelo fato de que o colunista trabalha para uma empresa jornalística e fala em nome dela, mas também o faz de modo personalístico, diferentemente do redator e do editorialista. Por sua vez, os artigos de opinião possuem uma autoria de caráter externo: articulistas são, em geral, representantes de prestígio social dos diversos segmentos profissionais dos grupos sociais. Já no caso das cartas de leitor, tem-se uma autoria também externa à empresa jornalística, mas, em geral, sem a marca de prestígio típica dos artigos. Em suma, a própria identidade dos gêneros pode ser apreendida com mais clareza e complexidade quando os interlocutores observam com mais atenção os modos como a autoria é concebida nas práticas sociais e como é materializada nos textos, a exemplo da assinatura, do pé biográfico e das marcas lingüísticas recorrentes para apontar (ou não) os autores empíricos.

O artigo de opinião se constitui como um gênero de discurso de caráter opinativo-argumentativo, o qual circula regularmente, de forma escrita, na esfera jornalística. Como já brevemente aludido acima, o que caracteriza o artigo, em contraste com os outros gêneros jornalísticos de caráter opinativo-argumentativo, é o fato de possuir uma autoria externa ao jornal, representada como de prestígio nos grupos sociais de elite e, portanto, aceita como tendo credibilidade para discutir temas relevantes 


\section{4}

no universo social e sobre eles emitir opinião (cf. RODRIGUES, 2001; MELO, 1994). Também é característico do artigo o fato de ele funcionar sofrendo a interposição da empresa jornalística, uma vez que esta é quem faz a seleção de quais articulistas terão seus textos publicados. Rodrigues (2001) denomina este funcionamento de autor interposto para caracterizar a ingerência que fazem as empresas jornalísticas com vistas à legitimação das figuras sociais que podem ter voz opinativa no espaço do artigo. Vêse, então, o quanto é restritivo e impróprio conceber a autoria como vinculada apenas ao indivíduo empírico que produz enunciados.

Já do ponto de vista ideológico, o artigo pode se prestar muito bem para, de modo indireto e não assumido explicitamente, fazer coro às próprias posições ideológicas do jornal, uma vez que empresas jornalísticas tendem a escolher como articulistas justamente aquelas figuras do universo social cujas posições axiológicas são confluentes com as suas. Por outro lado, o comprometimento e engajamento de uma empresa jornalística com participação social, práticas democráticas e ética social pode ser revelado, em boa medida, no modo como ela promove (ou não) a inserção de articulistas representantes de variados segmentos sociais. Dito de outro modo, o perfil sócio-político dos articulistas de cada jornal serve como um forte indicador das suas posições enunciativas e ideológicas. Uma vez que, como enfaticamente defendeu Bakhtin (1979a [1953]), os gêneros do discurso estão umbilicalmente ligados às esferas da atividade e comunicação humana, as quais tanto são refletidas como refratadas nos diversos tipos sócio-históricos de enunciados, uma forma interessante de entender o caráter ideológicoaxiológico do artigo de opinião é "mapear" de quais esferas sociais procedem os autores que estão ocupando a autoria desse gênero, observando como eles inscrevem, no pé biográfico, a esfera de onde provêm de modo a valorizar seu discurso. Ou seja, um "mapeamento" das esferas (dos articulistas) tanto recorrentemente presentes como ausentes pode, em grande medida, indiciar traços da própria posição axiológica da empresa jornalística.

Pelo fato de os jornais serem bens simbólicos comercializados a um custo razoavelmente elevado e de que os artigos, tanto para serem 
lidos como produzidos, pressuporem um elevado grau de letramento ${ }^{7}$ é que apenas alguns poucos segmentos sociais têm se apropriado do gênero artigo para difundir e reafirmar seus valores e crenças. Isso significa que grande contingente da sociedade moderna não está inserido nas práticas sociais de produção e consumo dos artigos de jornal. De um modo geral, podemos dizer que são apenas alguns indivíduos das classes A e B que sistematicamente participam da interação social promovida através dos artigos, embora haja casos incomuns de inclusão da classe C. Em suma, o artigo de jornal se constitui como um gênero de discurso típico de segmentos de elite das sociedades.

Rodrigues (2001, p. 143) demonstrou que o artigo de opinião tem como autor típico um colaborador externo, embora haja a presença - em menor escala - de autores jornalistas, caso em que escrevem como colaboradores externos e, por isso, mantêm o caráter típico da autoria no artigo. Quanto ao lugar social de que falam, a autora notou que há principalmente a presença de articulistas da esfera política, da indústria, do comércio, da administração, do clero e da esfera científico-acadêmica. Observou, ademais, que o articulista necessita ser percebido como de destaque e notoriedade profissional e social em sua esfera de atuação, o que explica porque a autoria do artigo é tão restritiva e até "profissionalizada", haja vista que, mesmo havendo em tese a abertura para uma grande diversidade de articulistas, são quase sempre os mesmos que publicam.

Rodrigues mostra que, justamente por ser um representante legitimado por sua esfera de atuação e não por sua vida privada, o articulista não fala diretamente em seu próprio nome, mas a partir do ponto de vista de sua esfera, o que faz com que seu discurso seja bivocal. Isso pode ser evidenciado de modo direto pelo pé biográfico, o qual freqüentemente informa a instituição a que o articulista pertence e em nome da qual fala.

O pé biográfico é um elemento verbal do artigo que aponta diretamente para a dimensão social dos enunciados pertencentes a este gênero. Ou melhor, o pé biográfico evidencia com muita clareza a

\footnotetext{
${ }^{7}$ Estamos tomando letramento como a capacidade de o sujeito se inserir efetivamente em práticas sociais de linguagem, sendo capaz de atribuir sentidos aos textos, de reagir enunciativamente a eles e de entender o seu funcionamento simbólico.
} 
relação indissociável entre a dimensão social e a dimensão verbal dos enunciados (cf. RODRIGUES, 2001). Isso se dá porque, por um lado, o pé biográfico passou a ser uma categoria textual que responde por um dos aspectos da estabilidade da composição textual dos artigos de jornal, de modo a funcionar como um elemento que contribui para o seu reconhecimento genérico. Já da perspectiva social, o pé biográfico ajuda a legitimar o caráter sócio-histórico da autoria nos artigos porque incorpora um conjunto de valorações sócio-ideológicas que, num dado lugar social, passam a ser usadas para legitimar a autoria no artigo e the conferir credibilidade e status de competência. Em tese, há uma vasta gama de informações acerca do articulista enquanto indivíduo empírico as quais podem compor o pé biográfico (dados profissionais, educacionais, culturais, acadêmicos, institucionais econômicos). Isso implica que sempre haverá escolhas por algumas delas em detrimento de outras e que estas escolha são de caráter sócio-histórico e não individualizadas, ou seja, os articulistas tendem a escolher informações que, num dado momento, são consideradas relevantes e potencialmente capazes de lhes conferir credibilidade para ocuparem a função de articulista.

\section{O PAPEL DO PÉ BIOGRÁFICO PARA A CONSTITUIÇÃO DA AUTORIA}

A amostra usada neste artigo consta de 90 artigos publicados nos jornais O Dia, Meio Norte e Diário do Povo do Piauí, que são os jornais de maior circulação no meio norte do Brasil ${ }^{8}$. A análise global desses 90 artigos, buscando identificar a que esferas os articulistas explicitamente se vinculam, via pé biográfico, mostrou que há a predominância das esferas da educação (27 casos), literária (23 casos), jornalística (21 casos) e jurídica (16 casos). Chama a atenção o fato de que as esferas predominantes têm em comum o fato de o exercício das profissões a elas

${ }^{8}$ O Meio Norte do Brasil é a região geográfica que inclui o estado do Piauí - sobretudo o Leste - e o Oeste do Maranhão. Esta região tem como centro político, econômico e cultural a cidade de Teresina, a qual oferece para a população do Meio Norte trabalho, educação e, sobretudo, serviços de saúde. Não é à toa que um dos nomes dos jornais é Meio Norte, o qual se propõe a oferecer informação que atenda a toda esta região. 
relacionadas lidarem sistematicamente com a escrita e com sua aprendizagem - tratam-se de esferas em que as práticas de escrita fazem parte sistematicamente do cotidiano profissional. Por outro lado, as três esferas mais representativas (educação, literária e jornalística) não são esferas que concentram elites economicamente poderosas, o que evidencia que, na imprensa de Teresina, a autoria no artigo de jornal é tipicamente ocupada por segmentos ligados às esferas culturais e educacionais.

Essa hipótese ganha força quando se faz o confronto entre as esferas presentes e as esferas de elite sistematicamente ausentes nos artigos publicados na imprensa de Teresina (esferas do empresariado, da política partidária, da indústria e da economia). Essa ausência pode ser tomada como uma forte evidência de que as elites econômicas e políticas não têm ocupado a posição enunciativa de articulistas para difundir suas orientações axiológicas acerca dos temas em debate. Um último dado interessante neste ponto: os poucos políticos que ocupam a autoria nos jornais pesquisados são pertencentes a outras regiões brasileiras (Brasília e Maranhão), já que, no período pesquisado, não foi publicado nenhum artigo de políticos representantes do Estado do Piauí. Entretanto, estes segmentos ausentes da posição de articulistas fazem-se presentes recorrentemente na posição de entrevistados nos telejornais locais.

Outra constatação importante é que a autoria é construída a partir da filiação a uma entidade de classe ou ao pertencimento a alguma instituição - o que é evidenciado pela presença marcante de siglas nos pés biográficos. O efeito enunciativo pode ser o seguinte: por pertencer a uma certa instituição, o articulista recebe autoridade e competência para tomar a palavra e, como conseqüência, isso pode criar no leitor uma prédisposição maior para conferir credibilidade ao tratamento temático e às posições axiológicas desses articulistas (em acordo com a proposta explicativa de RODRIGUES, 2001). É curioso ver nos dados que, mesmo quando o profissional se aposenta (delegado da PF aposentado, Funcionário aposentado do BB) ou quando se desliga da entidade (Ex Cons. e ex-presidente da OAB-PI, Ex-aluno, ex-professor e advogado do Dom Barreto, ex-presidente do Brasil), ele ainda invoca a instituição a que pertencera. Tal uso pode ser tomado como um forte indício de que, no universo pesquisado, a vinculação institucional e a esfera do trabalho têm um papel extremamente relevante na construção do ethos de 


\section{8}

competência do articulista, desempenhando um marcante papel enunciativo mesmo quando o articulista já dela se desligou.

Um outro subconjunto de pés biográficos é construído através da referência a várias profissões que um mesmo articulista desempenha simultaneamente (Odontólogo, membro da UBE - PI; Engenheiro e diretor admin. da Cepisa; Filólogo, filósofo e poeta; Advogado e administrador de empresas). Neste caso, o ethos de competência não decorre somente da sua vinculação institucional, mas, sobretudo, da indicação da competência do próprio indivíduo em diversas esferas de trabalho. Ou seja, o fato de desempenhar variadas profissões e, ao menos supostamente, dominar variados saberes, é enunciado pelo articulista para indicar ao leitor que ele se encontra diante de um autor abalizado para escrever competentemente sobre variados temas.

Esse caráter plural do exercício profissional aparece enunciado de dois modos nos dados: a) todas as profissões são mencionadas conjuntamente em todos os enunciados de um mesmo articulista; b) um mesmo articulista se intitula de modos diferentes em diferentes artigos. Neste segundo caso, torna-se relevante, em novas pesquisas, fazer um confronto entre a construção enunciativa do pé biográfico e os temas sobre os quais o articulista opina, a fim de observar se o recorte da categorização do articulista é sistematicamente elaborado em função da orientação temática ou se se trata de uma mera encenação da posição de autoria, no sentido de conferir credibilidade.

Também se apresenta como um dado relevante a presença recorrente, entre os articulistas, de estudantes e alunos universitários (Formanda em Pedagogia da UFPI, Alunos de jorn./FANOR, Graduado em Lic. Plena em História, Bac. em Direito, bacharel em Direito, Aluna do curso de Direito da FACID, Alunos do curso de Letras da UFPI), o que poderia ser tomado como um indício de que os jornais piauienses estariam cumprindo o papel democrático de possibilitar a expressão das orientações axiológicas de segmentos sociais não pertencentes às elites (não nos esqueçamos que nos jornais mais importantes do Brasil - a exemplo de Folha de S. Paulo, O Estado de São Paulo -, aos estudantes não é concedido espaço enunciativo para serem articulistas, ficando a eles reservado apenas o painel do leitor). Entretanto, nossa suposição é que, muito mais do que uma conquista dos estudantes ou uma concessão das empresas jornalísticas a este segmento, o que se dá, nos jornais 
pesquisados, é a ocupação de um vácuo deixado pelas elites econômicas, industriais e políticas. Os estudantes somente são alçados à posição de articulistas porque as figuras sociais das elites político-partidária e econômica abrem mão da posição enunciativa de articulistas, optando por ocupar outros lugares enunciativos (como entrevistados em programas televisivos).

\section{CONSIDERAÇÕES FINAIS}

Neste artigo discutimos, analisamos e exemplificamos a tese de que o pé biográfico se constitui num importante recurso para a construção enunciativa da autoria do articulista elaborada pelo próprio articulista, o que ilustra ser esta elaboração capaz tanto de refletir como de refratar o sujeito empírico que produz os artigos. Noutras palavras, o pé biográfico reflete, de algum modo, o sujeito empírico produtor do texto pelo fato de ser elaborado com base em dados da realidade e do perfil biográfico dos articulistas. Mas também refrata porque funciona como um argumento anexado ao texto a fim de conferir credibilidade aos pontos de vista nele apresentados, podendo induzir o interlocutor a construir uma imagem positiva do autor.

Também foi possível evidenciar neste estudo como o pé biográfico apresenta dados bastante relevantes para se entender o funcionamento dos gêneros do discurso, uma vez que esta categoria indicia a relação dialética entre a dimensão verbal e a dimensão social dos textos. Ou seja, o pé biográfico é um elemento verbal da composição dos artigos diretamente vinculado a características sócio-históricas dos articulistas, sendo uma das formas através das quais o gênero artigo de opinião possibilita a veiculação e legitimação de certos valores.

$O$ estudo também pode ser visto como um argumento em favor da tese de que a autoria não pode ser tomada como uma categoria relacionada unicamente à individualidade dos sujeitos, podendo ser mais bem compreendida se vista como de natureza simultaneamente individual e sócio-cultural. Em outras palavras, uma vez que os autores, em sua vida cotidiana, não são sujeitos homogêneos, mas sim múltiplos do ponto de vista social, profissional, cultural, religioso etc., o recorte 
dos traços que comporão o pé biográfico da figura do autor guia-se pelas avaliações axiológicas que o autor faz de si mesmo e pelas avaliações axiológicas predominantes em sua cultura.

\section{REFERÊNCIAS}

ALVES FILHO, F. A autoria nas colunas de opinião assinadas da Folha de S. Paulo. In: CAVALCANTE, M.; BRITO, M. A. P.; MIRANDA, T. P. (Orgs.). Teses e dissertações: Grupo Protexto. Fortaleza: Protexto-UFC, 2005. [publicação em CD-Rom].

.A autoria institucional em editoriais de jornal. Revista Alfa, v. 50, n. 1, p. 77-89, 2006.

BAZERMAN, C. Gêneros textuais, tipificação e interação. São Paulo: Cortez, 2005.

BATHIA, V. K. Genre analysys today. Revue belge de philology e d'historie, n. 75, p. 629-642, 1997.

BAKHTIN, M. Os gêneros do discurso. In: verbal. São Paulo: Martins Fontes, 1979a [1953]. . Estética da criação . O problema do texto In: . Estética da criação verbal. São

Paulo: Martins Fontes, 1979b [1953].

FOUCAULT, M. O que é um autor. Lisboa: Passagens, 1969.

MELO, J. M. A opinião no jornalismo brasileiro. 2. ed. rev. Petrópolis: Vozes, 1994.

RODRIGUES, R. H. A constituição e o funcionamento do gênero jornalístico artigo: cronotopo e dialogismo. 2001. 356f. Tese (Doutorado em Lingüística Aplicada) - LAEL/PUC-SP, São Paulo, 2001. Disponível em: www.lael.pucsp.br/lael/teses. Acesso em: 15 jul. 2002.

Recebido em 26/02/08. Aprovado em 30/07/08.

Title: The 'biographic footnote' and the constitution of authorship in newspaper articles

Author: Francisco Alves Filho

Abstract: This study aims at observing the constitution of authorship in newspaper 
articles when this constitution is produced by the article writers themselves, especially through the working out modes of 'biographic footnotes'. The corpus is composed of articles published in the newspapers O Dia, Meio Norte and Diário do Povo, all of which circulate in the Brazilian states of Maranhão and Piauí. Two regularities emerged from the researched materials: the fact that the same author creates different 'biographical footnotes' for his/her signed articles and the occurrence of 'biographic footnotes' containing data that emerge from and refer to the texts themselves. The constitution of authorship, as seen in the articles studied, points out to cultural traces of the social place where the newspapers circulate, one of the most important of them being the high value given to the academic degrees held by the article writers.

Keywords: newspaper article; authorship; biographic footnote; genre; newspaper.

Titre: La note biographique et la constitution de la fonction d'auteur dans des articles de journal

Auteur: Francisco Alves Filho

Résumé: Le but majeur de cette étude est l'observation du mode de constitution de la fonction d'auteur dans des articles de journal lors de la production par les articulistes eux-mêmes, surtout au moyen des formes d'élaboration de la note biographique. Le corpus est constitué par des articles publiés dans les journaux $\mathrm{O}$ dia, Meio Norte et Diário do Povo, qui circulent dans les états de Piauí et Maranhão (Brésil). Deux régularités ont émergé des données: le fait qu'un même auteur construit des différentes notes biographiques pour des différents textes signés par lui, et l'occurrence de notes biographiques contenant des données ressortissant de ces textes en se rapportant à eux en même temps. Par rapport à l'ensemble des articles sous investigation, la constitution de la fonction d'auteur signale des traits de la culture du lieu social où les journaux circulent, dont l'un est l'accent de valeur très marqué pour la formation académique des articulistes.

Mots-clés: article de journal; qualité d'auteur; note biographique; genre; journal.

Título: El pie biográfico y la constitución de la autoría en artículos periodísticos

Autor: Francisco Alves Filho

Resumen: El objetivo de este estudio es observar la constitución de la autoría en artículos de peridódico cuando su constitución es producida por los propios articulistas, especialmente a través de los modos de elaboración del pie biográfico. El cuerpo es constituído por artículos publicados en los periódicos O Dia, Meio Norte y Diário do Povo, los cuales circulan en los estados de Piauí y Maranhão. Dos regularidades emergieron del material investigado: el hecho de un mismo autor construir diferentes pies biográficos para diferentes textos por él firmados y la ocurrencia de pies biográficos conteniendo datos que emergen de los textos y reportan a los mismos textos. Vista en el conjunto de los artículos investigados, la constitución de la autoría apunta para rasgos de la cultura del lugar social donde los periódicos circulan, siendo uno de ellos el saliente acento valorativo conferido a la formación académica de los articulistas.

Palabras-clave: artículo periodístico; autoría; pie biográfico; género discursivo; periódico. 